\title{
Combining Chemometric Models with Adsorption Isotherm Measurements to Study Omeprazole in RP-LC
}

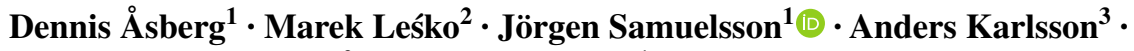 \\ Krzysztof Kaczmarski ${ }^{2}$ Torgny Fornstedt ${ }^{1}$ (i)
}

Received: 20 March 2016 / Revised: 21 June 2016 / Accepted: 26 June 2016 / Published online: 12 August 2016

(C) The Author(s) 2016. This article is published with open access at Springerlink.com

\begin{abstract}
The adsorption of the proton-pump inhibitor omeprazole was investigated using RP-LC with chemometric models combined with adsorption isotherm modelling to study the effect of $\mathrm{pH}$ and type of organic modifier (i.e., acetonitrile or methanol). The chemometric approach revealed that omeprazole was tailing with methanol and fronting with acetonitrile along with increased fronting at higher $\mathrm{pH}$. The increased fronting with higher $\mathrm{pH}$ for acetonitrile was explored using a pH-dependent adsorption isotherm model that was determined using the inverse method and it agreed well with the experimental data. The model indicated that the peaks exhibit more fronting at high $\mathrm{pH}$ due to a larger fraction of charged omeprazole molecules. This model could accurately predict the shape of elution profiles at arbitrary $\mathrm{pH}$ levels in the studied interval. Using a two-layer adsorption isotherm model, the difference between acetonitrile and methanol was studied at the lowest $\mathrm{pH}$ at which almost all omeprazole molecules are neutral. Omeprazole had adsorbate-adsorbate interactions that were similar in strength for the acetonitrile and methanol mobile phases, while the solute-adsorbent interactions
\end{abstract}

Electronic supplementary material The online version of this article (doi:10.1007/s10337-016-3151-8) contains supplementary material, which is available to authorized users.

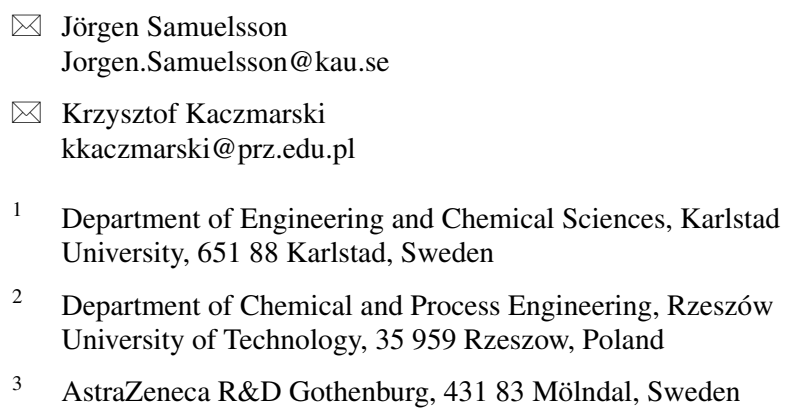

1 Department of Engineering and Chemical Sciences, Karlstad University, 65188 Karlstad, Sweden

2 Department of Chemical and Process Engineering, Rzeszów University of Technology, 35959 Rzeszow, Poland

3 AstraZeneca R\&D Gothenburg, 43183 Mölndal, Sweden

were almost twice as strong with methanol. The difference in the relative strengths of these two interactions likely explains the different peak asymmetries (i.e., tailing/fronting) in methanol and acetonitrile. In conclusion, thermodynamic modelling can complement chemometric modeling in HPLC method development and increase the understanding of the separation.

Keywords Liquid chromatography $\cdot \mathrm{pH} \cdot$ Adsorption isotherm $\cdot$ Design of experiments $\cdot$ Omeprazole

\section{Introduction}

The pharmaceutical industry quality control (QC) methods, used continuously to release product batches for market, must be validated and then approved by regulatory agencies, such as the US Food and Drug Administration (FDA) [1]. To enable minor post-approval variations to be made to approved QC methods without having to alert regulators, the quality by design $(\mathrm{QbD})$ concept was introduced several years ago [2]. A variant of this approach is a QC-method enhancement concept, where a clear boundary regarding critical attributes is defined together with a principle of the testing technique and an exemplified QC method. In addition to this, an extended robustness testing using the design of experiment $(\mathrm{DoE})$ is required. By doing this, a regulatory flexibility can be given based on the presentation of a deeper scientific knowledge regarding the actual QC method $[2,3]$. In QbD, the use of chemometric modeling is encouraged and has become a key strategy $[4,5]$. When DoE is used in analytical QbD, the goal is to establish a method operable design region (MODR), where the method performance criteria are met and where variations in responses are understood. Inside the MODR, it is 
then possible to change experimental conditions without further validation or regulatory interaction $[6,7]$.

Sometimes other tools, based on firm physicochemical theory are needed to obtain the necessary scientific understanding of a process, especially when considering chromatographic methods. In liquid chromatography, adsorption equilibrium information about a pure component is the most important piece of information for understanding an adsorption process regardless of how many components are present in the system [8]. Recent research has illustrated the importance of investigating adsorption isotherms for understanding the adsorption processes in analytical as well as preparative chromatographic systems [9-13].

Previously, we have studied the proton-pump inhibitor omeprazole [14] in a case study of the method transfer from HPLC to UPLC $[13,15,16]$. The QC method for omeprazole was thoroughly validated in accordance with the ICH guidelines [16]. It was observed, but not reported, that $\mathrm{pH}$ was important for the peak shape and retention of omeprazole and that overloaded elution profiles of omeprazole were "anti-Langmuirian"-shaped (type-III [17]) when using acetonitrile as organic modifier. It was also noted that changing the organic modifier to methanol resulted in "Langmuirian"-shaped (type-I [17]) elution profiles. These observations agree with earlier observations that "Langmuirian"-shaped isotherms are found with the use of methanol and S-shaped isotherms that are common with acetonitrile [18]. This was proposed to be because of a multilayer of acetonitrile adsorbing on the surface of the stationary phase compared to the single layer of methanol. To describe the $\mathrm{pH}$ dependence, Gritti and Guiochon have developed a model for acidic and basic compounds close to their $\mathrm{p} K_{\mathrm{a}}$ values taking into account their ionization equilibria [19-21]. Changes in the adsorption mechanism due to the nature of the organic modifier and $\mathrm{pH}$ are important to consider, but are difficult to study using only the linear part of the adsorption isotherm (using diluted samples). Therefore, we propose also studying the nonlinear part of the adsorption isotherm to get a more complete understanding.

Our aim is to investigating the adsorption of omeprazole as a function of $\mathrm{pH}$ and type of organic modifier using a combined DoE and adsorption isotherm approach. We will illustrate how adsorption isotherm modeling can complement chemometric modeling using DoE to obtain a firmer understanding of the separation system.

\section{Theory}

The solute concentrations in the mobile $(C)$ and stationary $(q)$ phases are related through the adsorption isotherm, and in this work, two adsorption models were used: a two-layer adsorption isotherm model [22] and a model taking the degree of omeprazole ionization into account [19-21], here denoted the $\mathrm{pH}$-dependent model, since the degree of ionization depends on $\mathrm{pH}$. The two-layer adsorption isotherm model assumes that adsorbate-adsorbate interactions occur and can be expressed as [22-24]

$q=q_{\mathrm{s}} \frac{b_{\mathrm{S}} C+2 b_{\mathrm{S}} b_{\mathrm{L}} C^{2}}{1+b_{\mathrm{S}} C+b_{\mathrm{S}} b_{\mathrm{L}} C^{2}}$,

where $q_{\mathrm{s}}$ is the saturation capacity, $b_{\mathrm{S}}$ is the association equilibrium constant at the adsorbent surface, and $b_{\mathrm{L}}$ is the association equilibrium constant on the first adsorbed layer to the column surface. The two-layer model is an expansion of the Langmuir model incorporating adsorbate-adsorbate interactions between the first established adsorbed solute layer and non-adsorbed solute molecules. Equation (1) is mathematically equivalent to the quadratic [25] and the Moreau [26] adsorption isotherms, but is derived under different assumptions. The adsorption isotherm model that takes omeprazole ionization into account is expressed as [19-21]

$q=\frac{\left(a_{\mathrm{c}}(1-\alpha)+a_{\mathrm{n}} \alpha\right) C}{1+\left((1-\alpha) b_{\mathrm{c}}+\alpha b_{\mathrm{n}}\right) C}$,

$q=\frac{\left(a_{\mathrm{c}}(1-\alpha)+a_{\mathrm{n}} \alpha\right) C}{1-\left((1-\alpha) b_{\mathrm{c}}+\alpha b_{\mathrm{n}}\right) C}$,

where $a$ and $b$ are adsorption isotherm parameters. Derived from the general Langmuir model, Eq. (2a) yields Langmuirian peak shapes and Eq. (2b) yields anti-Langmuirian peak shapes [27]. Indices $\mathrm{c}$ and $\mathrm{n}$ denote the charged and uncharged fractions of omeprazole, respectively, while $\alpha$ is the fraction of uncharged omeprazole that is, implicitly, a function of $\mathrm{pH}$. In this study, the mobile phase was weakly buffered and the local $\mathrm{pH}$ in the solute band depended on the solute concentration at high loads [19-21].

The set of parameters in the adsorption isotherm model was determined using the inverse method [27] for each experimental condition. In the inverse method, the parameters are estimated by minimizing the sum of squared differences between the experimental and calculated elution profiles [28]. Elution profiles were calculated using the equilibrium-dispersive (ED) model [27], which can be expressed as

$\frac{\partial C}{\partial t}+F \frac{\partial q}{\partial t}+\frac{u}{\varepsilon_{t}} \frac{\partial C}{\partial z}=D_{\mathrm{a}} \frac{\partial^{2} C}{\partial z^{2}}$,

where $F=\left(1-\varepsilon_{\mathrm{t}}\right) / \varepsilon_{\mathrm{t}}$ is the phase ratio, $\varepsilon_{t}$ is the total porosity, $u$ is the superficial velocity, $D_{\mathrm{a}}$ is the apparent dispersion coefficient, $t$ and $z$ are the time and axial positions in the column, respectively, and $C$ and $q$ are the local mobile and stationary phase solute concentrations, respectively. The orthogonal collocation on the finite-element method [29] was used to discretize the spatial derivatives of 
the ED model, while the Adams-Moulton method implemented in the VODE procedure [30] was used to solve the system of ordinary differential equations. At $t=0$, the stationary phase was in equilibrium with the pure mobile phase. Danckwerts boundary conditions were used at the column inlet and outlet [27] with an experimentally obtained injection profile [13]. The minimization was done using a modified least square Marquardt algorithm [31]. Calibration from response to concentration for the experimental elution profiles was done by fitting the different column loads for each experimental condition, so that the injected mass equaled the eluted mass [13].

\section{Materials and Methods}

\section{Chemicals}

Gradient grade acetonitrile (VWR International, Radnor, PA, USA) and HPLC grade methanol (Fischer Scientific, Loughborough, UK) were used as organic modifiers. Water with a conductivity of $18.2 \mathrm{M} \Omega \mathrm{cm}$ from a Milli-Q Plus 185 water purification system (Merck Millipore, Billerica, MA, USA), analytical grade sodium phosphate dibasic dihydrate, sodium phosphate monobasic dihydrate (SigmaAldrich, St. Louis, MO, USA), and ammonium bicarbonate (99 \%; J.T. Baker, Deventer, Netherlands) were used to prepare the aqueous buffers. The solutes were omeprazole ( $>99 \%$ ), methyl-omeprazole (analytical reference standard), and omeprazole sulfone (analytical reference standard) and were gifts from AstraZeneca R\&D (Mölndal, Sweden). The column hold-up volume was determined by means of pycnometry [32] using acetonitrile and dichloromethane. The aqueous buffers and sample solutions were filtered through a $0.2-\mu \mathrm{m}$ nylon filter membrane (Whatman, Maidstone, UK) before use.

\section{Instrumentation}

The experiments were performed on an Agilent 1200 chromatograph (Agilent Technologies, Palo Alto, CA, USA) equipped with a binary pump, an auto sampler with a 900$\mu \mathrm{L}$ sample loop, a diode-array UV-detector, and a thermostated column oven. The extra column volume from the auto sampler to the detector was $0.039 \mathrm{~mL}$ and was subtracted from the experimental data. The column was a $100 \mathrm{~mm} \times 4.6 \mathrm{~mm}$ XBridge BEH $\mathrm{C}_{18}$ column (Waters, Milford, MA, USA) with an average particle diameter of $3.5 \mu \mathrm{m}$. Two columns were used, the first in the DoE part and the second in all other experiments, with column holdup volumes of 1.055 and $0.925 \mathrm{~mL}$, respectively. The flow rates were 1.0 and $0.7 \mathrm{~mL} \mathrm{~min}^{-1}$ for the acetonitrile and methanol mobile phases, respectively. Analytical peaks were detected at $302 \mathrm{~nm}$, while overloaded peaks were detected at $342 \mathrm{~nm}$.

\section{Procedure}

The mobile phases used were either 25/75, v/v, acetonitrile/ aqueous buffer or $45 / 55, \mathrm{v} / \mathrm{v}$, methanol/aqueous buffer. The aqueous buffers were $15 \mathrm{mM}$ phosphate buffer of $\mathrm{pH} 7.0$ 9.0 in the DoE part and adsorption isotherm experiments; when estimating the $\mathrm{p} K_{\mathrm{a}}$ values, $15 \mathrm{mM}$ ammonium bicarbonate buffers of $\mathrm{pH}$ between 9.0 and 11.0 were used along with an additional phosphate buffer of $\mathrm{pH}$ 6.0.

${ }_{\mathrm{w}}^{\mathrm{s}} \mathrm{pH}$ is $\mathrm{pH}$ measured in the eluent containing the organic modifier, i.e., measured directly in the eluent, although the $\mathrm{pH}$-electrode is calibrated with water solutions [33]. To experimentally estimate the ${ }_{\mathrm{w}}^{\mathrm{s}} \mathrm{p} K_{\mathrm{a}}$ values of omeprazole and omeprazole sulfone, which both behave as monoprotic acids in the investigated $\mathrm{pH}$ range, at $30{ }^{\circ} \mathrm{C}$, the retention factor at different ${ }_{\mathrm{w}}^{\mathrm{s}} \mathrm{pH}$ values were obtained and the results were fitted to the approximate model [34]:

$k=\frac{k_{0}+k_{1} \times 10^{\mathrm{pH}-\mathrm{p} K_{\mathrm{a}}}}{1+10^{\mathrm{pH}-\mathrm{p} K_{\mathrm{a}}}}$,

where $k_{0}$ and $k_{1}$ are the retention factors for the acid and basic forms, respectively. Seven different $\mathrm{pH}$ levels were used for the acetonitrile case, and eight different $\mathrm{pH}$ levels were used for the methanol case. The retention factor was determined with three replicate measurements at each $\mathrm{pH}$ level. Equation (4) neglects changes in the surface properties of the adsorbents, but is sufficiently accurate to estimate the $\mathrm{p} K_{\mathrm{a}}$ values of specific solvent mixtures and temperatures in the ${ }_{\mathrm{w}}^{\mathrm{s}} \mathrm{pH}$ range applicable here.

Column temperature $\left(20-40{ }^{\circ} \mathrm{C}\right)$ and $\mathrm{pH}\left({ }_{\mathrm{w}}^{\mathrm{w}} \mathrm{pH}\right.$ 7.0-9.0) were chosen as factors in the experimental design, which was a full factorial design in three levels with three center points. For each run, $10-\mu \mathrm{L}$ samples containing $0.15 \mathrm{mg} \mathrm{mL} \mathrm{m}^{-1}$ omeprazole, $0.011 \mathrm{mg} \mathrm{mL} \mathrm{m}^{-1}$ omeprazole sulfone, and $0.007 \mathrm{mg} \mathrm{mL}^{-1}$ methyl-omeprazole were injected in duplicate. The diluent was the corresponding mobile phase for each run. As responses, the retention and resolution factors for all components and the tailing factor for omeprazole were used. Regression models were constructed in the software MODDE 7 (Umetrics, Sweden) after first removing outliers and insignificant coefficients at a $95 \%$ confidence level.

To determine the adsorption isotherm of omeprazole at different $\mathrm{pH}$ levels, overloaded, duplicate injections of 300,400 , and $500 \mu \mathrm{L}$ were made at five $\mathrm{pH}$ levels in the same range as used in the DoE. The column temperature was $30^{\circ} \mathrm{C}$, and the experiments were performed with either acetonitrile or methanol as organic modifier. The omeprazole concentration was $2.5 \mathrm{mg} \mathrm{mL}^{-1}$ with the acetonitrile mobile phase and $4.0 \mathrm{mg} \mathrm{mL}^{-1}$ with the methanol mobile phase, while the diluent was the mobile phase. 
<smiles>COc1ccc2nc(S(=O)Cc3ncc(C)c(OC)c3C)[nH]c2c1</smiles>

A. Omeprazole

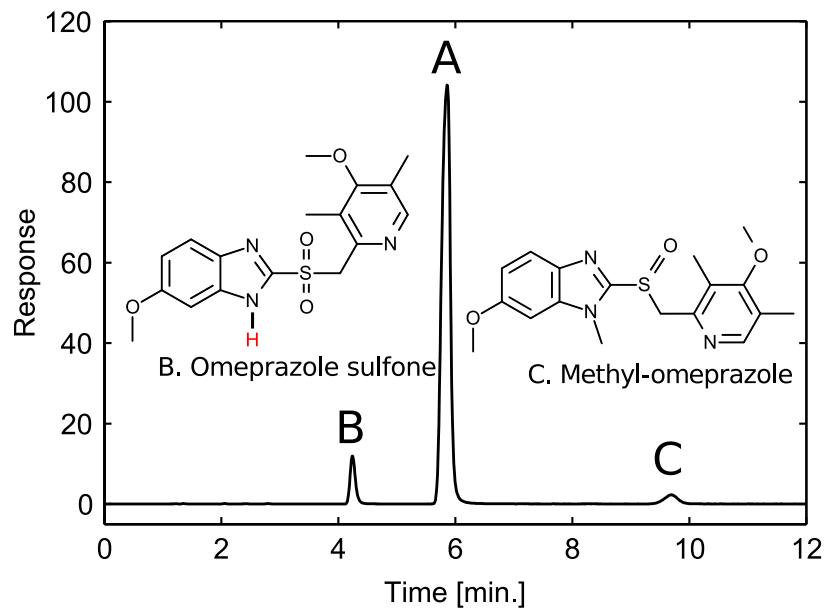

Fig. 1 Structure of the omeprazole and the investigated impurities along with the chromatogram obtained at the center point (buffer ${ }_{\mathrm{w}}^{\mathrm{w}} \mathrm{pH}=8.0,30^{\circ} \mathrm{C}$ ) of the experimental design with acetonitrile as organic modifier. The flow rate was $1.0 \mathrm{~mL} \mathrm{~min}{ }^{-1}$, the detection was conducted at $302 \mathrm{~nm}$, and the injection was $10 \mu \mathrm{L}$ of $0.15 \mathrm{mg} \mathrm{mL}^{-1}$ omeprazole, $0.011 \mathrm{mg} \mathrm{mL}^{-1}$ omeprazole sulfone, and $0.007 \mathrm{mg} \mathrm{mL}^{-1}$ methyl-omeprazole. The hydrogen of the benzimidazole group lost at high $\mathrm{pH}$ for omeprazole and omeprazole sulfone is indicated in red

\section{Results and Discussion}

\section{Chemometric Modeling}

The design region was chosen to span common HPLC temperatures and a relevant $\mathrm{pH}$ range for the separation system (omeprazole quickly degrades below 7 [35]). From the full factorial design, excellent regression models could be determined for all responses. The regression coefficients and statistics are presented in Electronic Supplementary Material Tables S1 and S2. The structures of the solutes and the chromatogram of the center point with acetonitrile are shown in Fig. 1. From the regression models, response surfaces were constructed for each response. Figure $2 \mathrm{a}, \mathrm{b}$ shows the retention factors for omeprazole with acetonitrile and methanol as organic modifiers, respectively, with $\mathrm{pH}$ being the most important factor. The same trends are present for acetonitrile and methanol, i.e., increasing $\mathrm{pH}$ and temperature reduces the retention factor, but temperature has a comparatively larger effect with methanol. Omeprazole sulfone behaves similarly to omeprazole (Electronic Supplementary Material Fig. S1), i.e., the retentions are decreasing with increasing temperature and $\mathrm{pH}$. For omeprazole and omeprazole sulfone, the retention factor decreases with increasing $\mathrm{pH}$, because the hydrogen on the benzimidazole group is lost at high $\mathrm{pH}$ (Fig. 1) and the molecules go from being neutral to being negatively charged. Since the stationary phase is apolar and the mobile-phase polar in RP-LC, charged compounds are less retained than
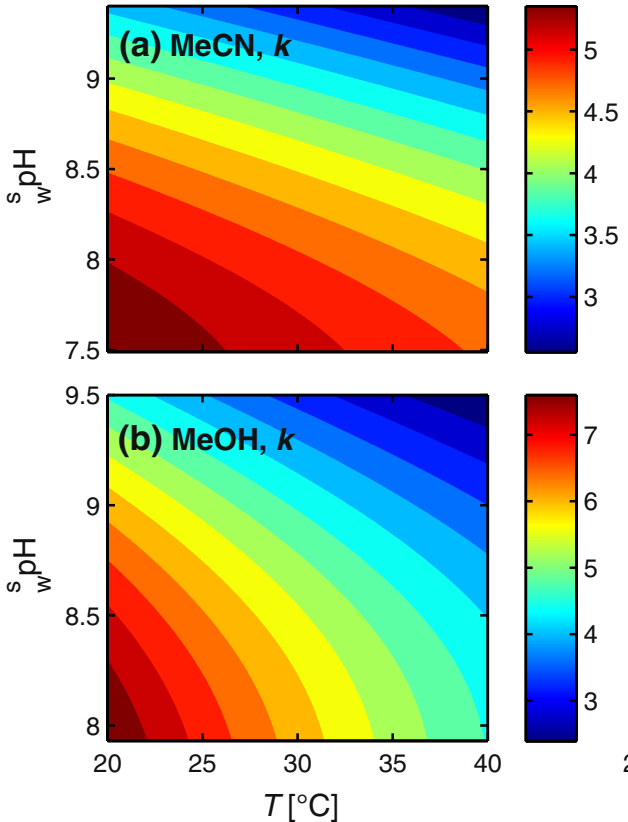
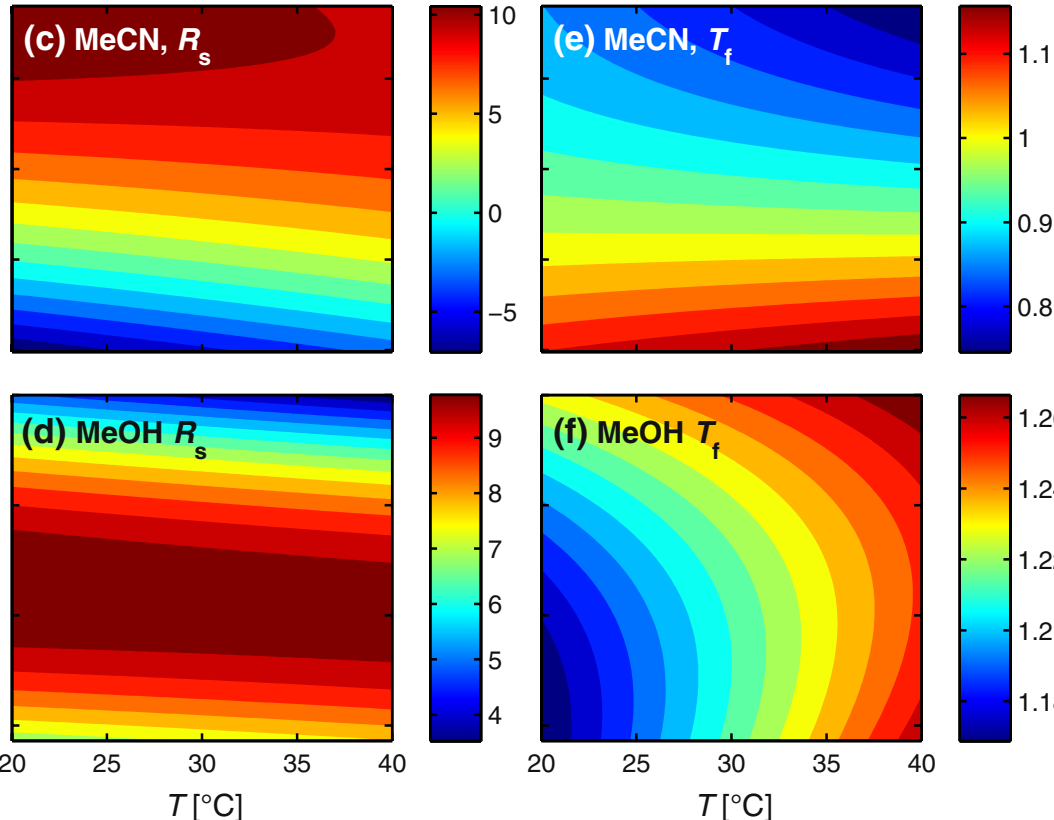

Fig. 2 Response surfaces from the experimental designs with acetonitrile (a, c, e) and methanol (b, d, f) as organic modifier. a, b Retention factors, $k$, of omeprazole, $\mathbf{c}, \mathbf{d}$ resolution factors, $R_{\mathrm{s}}$, between omeprazole and H168/66, and $\mathbf{e}, \mathbf{f}$ tailing factors, $T_{\mathrm{f}}$, of omeprazole 
neutral ones. The $\mathrm{p} K_{\mathrm{a}}$ values for omeprazole and omeprazole sulfone in the mobile phase at $30{ }^{\circ} \mathrm{C}$ were determined experimentally by measuring the retention factors with three replicates at different $\mathrm{pH}$ values and fitting the data to Eq. (4), and the results are shown in Fig. 3. The $\mathrm{p} K_{\mathrm{a}}$ values, given with $95 \%$ confidence intervals, for omeprazole were $9.21 \pm 0.16$ and $9.18 \pm 0.14$ with acetonitrile and methanol, respectively. For omeprazole sulfone, the $\mathrm{p} K_{\mathrm{a}}$ values were $8.15 \pm 0.03$ and $8.38 \pm 0.29$ with acetonitrile and methanol, respectively. The temperature dependence of the $\mathrm{p} K_{\mathrm{a}}$ value for the phosphate buffer is -0.0028 units $/ \mathrm{K}$ [36] and can be neglected in the studied temperature interval. For secondary amines, it is around -0.01 units/K [37], giving a change of \pm 0.1 units in the design region due to temperature. For methyl-omeprazole, the retention factor is almost unaffected by $\mathrm{pH}$, since the acidic hydrogen on the benzimidazole group is replaced with a methyl group.

Figure 2c, $d$ shows response surfaces for the resolution factor between omeprazole and omeprazole sulfone. For acetonitrile, the elution order is changed with the peaks co-eluting around ${ }_{\mathrm{w}}^{\mathrm{s}} \mathrm{pH}=7.8$, while for methanol, omeprazole always elutes after omeprazole sulfone with a maximum resolution factor at around ${ }_{\mathrm{w}}^{\mathrm{s}} \mathrm{pH}$ 8.5. In both the cases, $\mathrm{pH}$ is the most important factor with temperature playing a minor role. The difference in $\mathrm{p} K_{\mathrm{a}}$ can quantitatively account for the reversal of peak order observed in Fig. 2c (cf. Fig. 3). The resolution factors between omeprazole and methyl-omeprazole versus $\mathrm{pH}$ and temperature are shown in Electronic Supplementary Material Fig. S2. For acetonitrile, the temperature is not significant, leading to a one-factor model in which the resolution factor increases with $\mathrm{pH}$, but is never below nine. With methanol, on the other hand, omeprazole and methyl-omeprazole nearly coelutes at the lowest $\mathrm{pH}$ and temperature indicating a change in selectivity when switching modifier. One reason for this is that acetonitrile forms a double layer on the stationary phase surface, while methanol forms a monolayer [18]. The differences between acetonitrile and methanol will be discussed further in "Adsorption isotherm modeling".

Response surfaces for the peak tailing, calculated according to the USP definition, are shown in Fig. 2e and $\mathrm{f}$. With acetonitrile as modifier, the peak is tailing at low $\mathrm{pH}$ and fronting (i.e., a tailing factor below one) at high $\mathrm{pH}$ with the temperature only playing a minor role. Methanol, in contrast, gives only tailing peaks (i.e., tailing factor above one) with temperature being the most important factor. This difference cannot be directly explained from the observations in the DoE investigation. By injecting samples of different concentrations and observings if the peak shape changes, it is possible to get an indication if the origin of the peak asymmetry is thermodynamic or kinetic. The results are presented in Fig. 4, where three concentrations of omeprazole are injected at ${ }_{\mathrm{w}}^{\mathrm{s}} \mathrm{pH} 9.38$ and $40{ }^{\circ} \mathrm{C}$. The
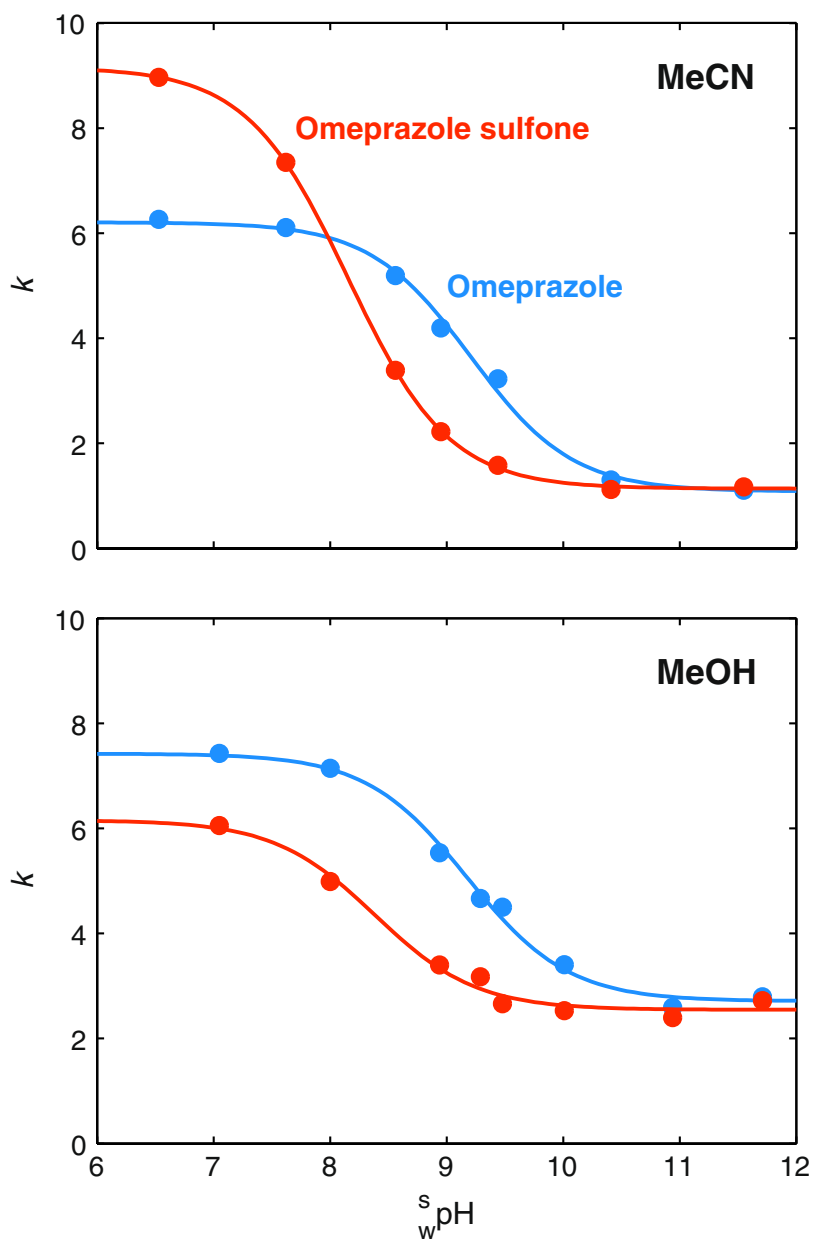

Fig. 3 Estimation of $\mathrm{p} K_{\mathrm{a}}$ values for omeprazole and omeprazole sulfone in 25/75, v/v, acetonitrile/water and 45/55, v/v methanol/water at $30{ }^{\circ} \mathrm{C}$. Symbols are experimental retention factors at different mobile phase ${ }_{\mathrm{w}}^{\mathrm{s}} \mathrm{pH}$ levels and solid lines are the best fit to Eq. (4)

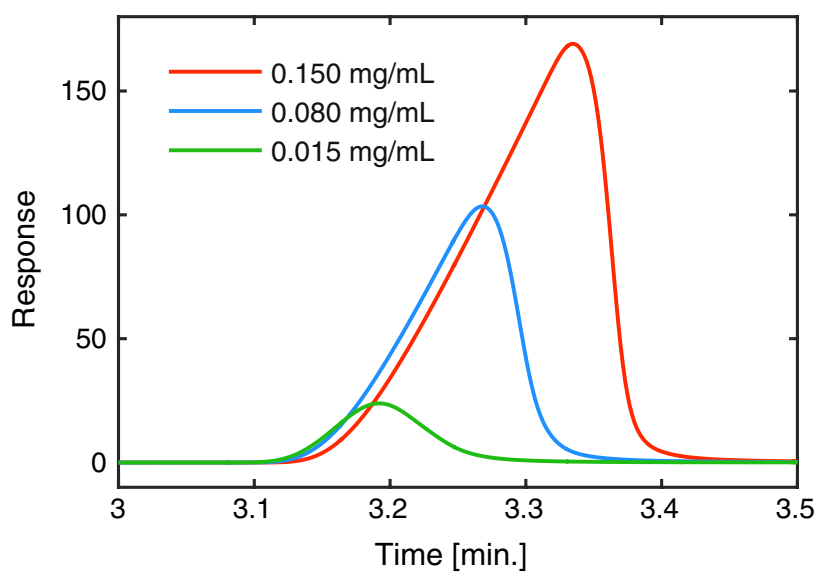

Fig. 4 Elution profiles of omeprazole using different sample concentrations to illustrate that the fronting is due to thermodynamic overloading. The mobile phase with $25 / 75$, v/v, acetonitrile/phosphate buffer $\left({ }_{\mathrm{w}}^{\mathrm{w}} \mathrm{pH}=9.0\right)$ at a temperature of $30^{\circ} \mathrm{C}$ and flow rate of $1.0 \mathrm{~mL} /$ $\min$ 
peaks clearly become more symmetrical when the concentration is decreasing; therefore, the underlying reason for the peak asymmetry is likely of thermodynamic in nature [27]. Note that in QC methods, it is often necessary to have concentrations in the $0.1 \mathrm{mg} / \mathrm{mL}$ range of the active pharmaceutical ingredient to obtain sufficiently high signals for the impurities $[38,39]$.

\section{Adsorption Isotherm Modeling}

This section seeks to explain the reason for the peak asymmetry observed in Fig. 2e and $\mathrm{f}$ due to $\mathrm{pH}$. To do this, the adsorption isotherms for omeprazole, with methanol and acetonitrile as organic modifiers, were determined directly from overloaded elution profiles using the inverse method. Experimental overloaded elution profiles are shown in Fig. 6 (blue lines). The profile with acetonitrile as modifier is "anti-Langmuirian" in shape having a diffuse front and a sharp rear, and at ${ }_{\mathrm{w}}^{\mathrm{s}} \mathrm{pH}$ values above 9, the diffuse front of the elution profile is increasingly curved. With methanol as modifier, at ${ }_{\mathrm{w}}^{\mathrm{s}} \mathrm{pH}$ values up to approximately 9 , the elution profiles are "Langmuirian" in shape having a sharp front and a diffuse rear.

When determining adsorption isotherms using the inverse method, one must properly select an adsorption isotherm model a priori. One important characteristic of the adsorption isotherm is the number of adsorption sites, usually determined from the adsorption energy distribution (AED) obtained from experimental data using, for example, the frontal analysis (FA) [27]. The AED for omeprazole, using the same stationary and mobile phases $\left({ }_{\mathrm{w}}^{\mathrm{s}} \mathrm{pH} \approx 8.5\right)$ as in this work, was previously determined from FA [13] and found to be unimodal, i.e., containing only one type of adsorption site. Since the DoE investigation revealed that the retention factor was strongly $\mathrm{pH}$ dependent and that the $\mathrm{p} K_{\mathrm{a}}$ value of omeprazole was inside the studied $\mathrm{pH}$ range, the adsorption model should take $\mathrm{pH}$ into account. Furthermore, when injecting large amounts of omeprazole, the buffer had insufficient capacity to keep the $\mathrm{pH}$ constant, so the $\mathrm{pH}$ will depend on the local omeprazole concentration.

One adsorption isotherm model accounting for this situation is the pH-dependent model, Eq. (2), derived by Gritti and Guiochon [19-21]. Rather, lengthy calculations are needed to determine the function $\alpha(C)$, i.e., the fraction of uncharged omeprazole molecules as a function of the total omeprazole concentration. Using activity coefficients and the ${ }_{\mathrm{w}}^{\mathrm{s}} \mathrm{p} K_{\mathrm{a}}$ derived in the previous section, the results for the highest $\mathrm{pH}$ cases are shown in Fig. 5 and the calculations are described in detail in the Electronic Supplementary Material. The pH-dependent isotherm model, Eq. (2), has the advantage that only one set of parameters is needed for modeling at arbitrary $\mathrm{pH}$ (i.e., in the inverse method) and only elution profiles at the highest and lowest
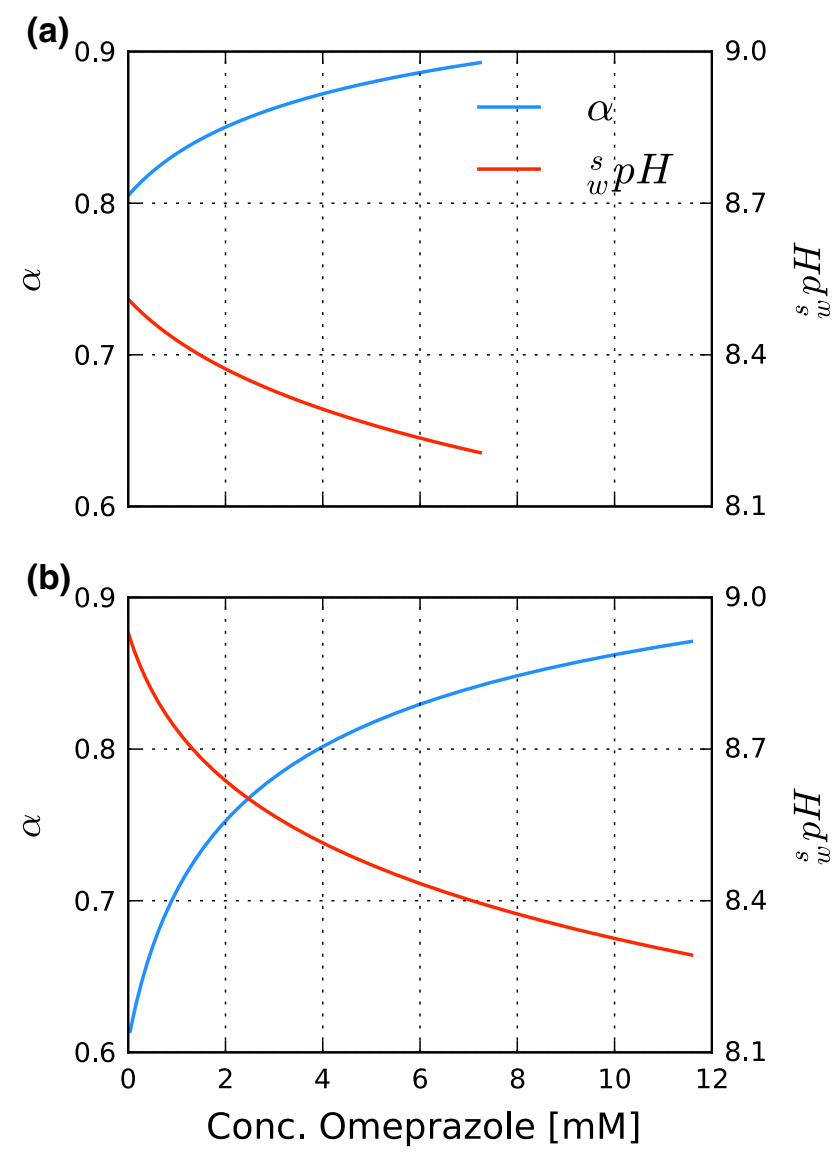

Fig. 5 Fraction of the neutral form of omeprazole, $\alpha$, and ${ }_{w}^{\mathrm{s}} \mathrm{pH}$ versus the concentration of omeprazole in the mobile phase with a 25/75, $\mathrm{v} / \mathrm{v}$, acetonitrile/phosphate buffer $\left({ }_{\mathrm{w}}^{\mathrm{w}} \mathrm{pH}=9.0\right)$ and $\mathbf{b} 45 / 55$, v/v, methanol/phosphate buffer $\left({ }_{\mathrm{w}}^{\mathrm{w}} \mathrm{pH}=9.0\right)$

$\mathrm{pH}$ levels being needed. The estimated sets of parameters for acetonitrile, Eq. (2b), and methanol, Eq. (2a), are presented in Electronic Supplementary Material Table S3 along with some details of the estimation procedure. The agreement between calculated and experimental elution profiles was good in both methanol and acetonitrile (see red lines in Fig. 6). Note that the intermediate pH in Fig. 6 was not used in the inverse method; the profiles at this level are predictions and, therefore, agree somewhat less with the experimental elution profiles. That the $\mathrm{pH}$-dependent isotherm was able to describe the experimental elution profiles well lends strength to the proposed mechanism that the relationship between the charged and uncharged forms of omeprazole causes the increased fronting at high $\mathrm{pH}$. When the charged form increases at high $\mathrm{pH}$, the elution profiles become more deformed, with parts of the front starting to move faster than the rest of the profile. We concluded that the increased fronting of the omeprazole peaks with increased $\mathrm{pH}$ seen in the DoE investigation with acetonitrile as modifier can be explained by thermodynamic 

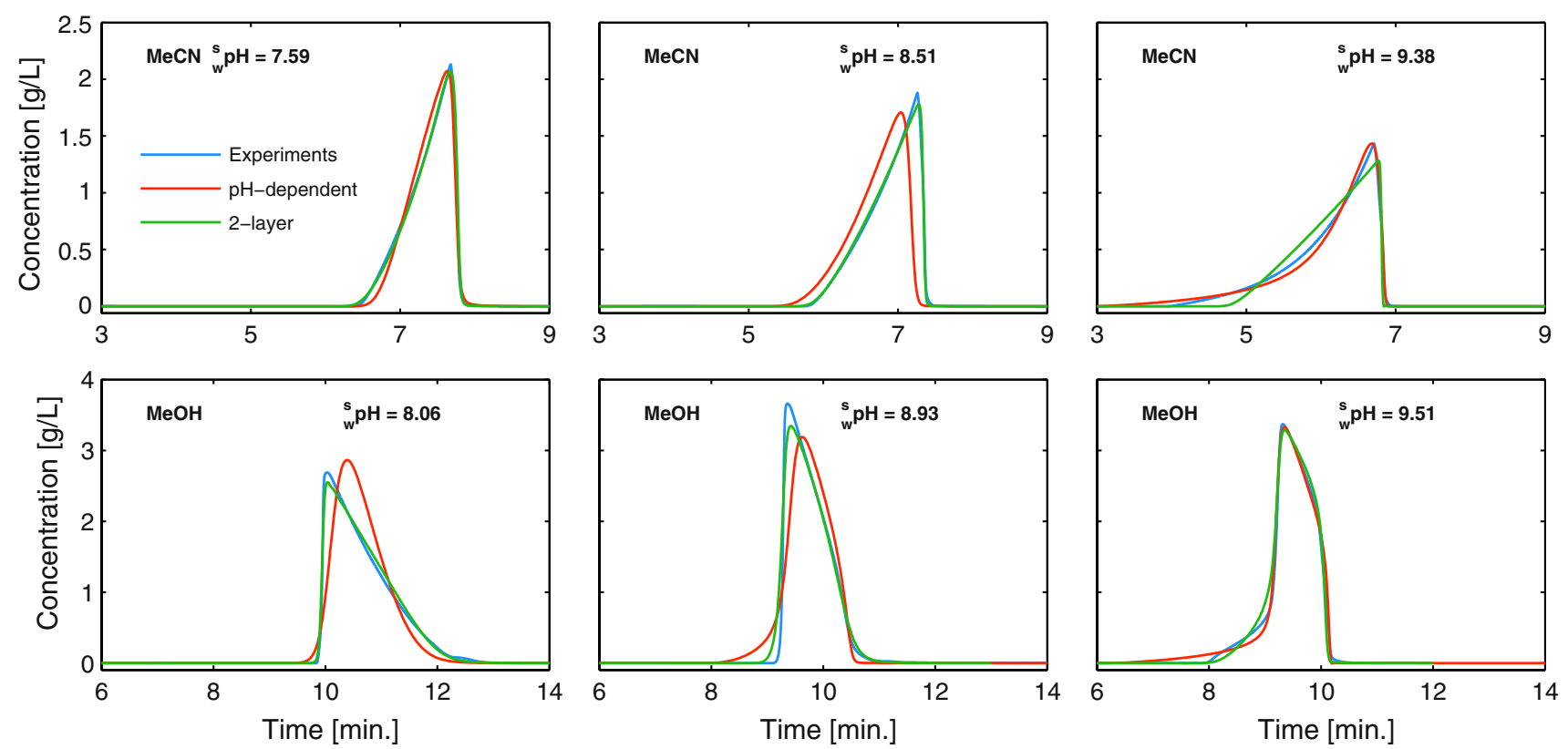

Fig. 6 Comparison between experimental elution profiles (blue lines) and elution profiles calculated using the $\mathrm{pH}$-dependent isotherm model (red lines) and the quadratic isotherm model (green lines) for omeprazole at different $\mathrm{pH}$ levels. In a-c $25 / 75$, v/v, acetonitrile/phosphate buffer is used as mobile phase, and in $\mathbf{d}-\mathbf{f} 45 / 55$, $\mathrm{v} / \mathrm{v}$, methanol/phosphate buffer is used as mobile phase. For acetoni-

overloading combined with variation in the local eluent $\mathrm{pH}$ due to the weakly buffered mobile phase.

To study the difference between methanol and acetonitrile, we consider the case in which most (>95\%) omeprazole molecules are uncharged, i.e., at the lowest $\mathrm{pH}$ (buffer $\mathrm{pH}$ 7.0). The two-layer isotherm model, Eq. (1), is fitted to each $\mathrm{pH}$ separately to obtain individual sets of parameters. At higher $\mathrm{pH}$ where the fraction of uncharged omeprazole decreases, the two-layer isotherm should only be seen as an empirical model, since it does not take into account the charge of omeprazole or the variation in the local eluent $\mathrm{pH}$ due to the weakly buffered mobile phase. However, at the lowest $\mathrm{pH}$, it can yield certain physiochemical insights. The adsorption isotherm parameters for the two-layer isotherm is presented in Electronic Supplementary Material Table $\mathrm{S} 4$, and compared with the parameters at the lowest $\mathrm{pH}$ for methanol and acetonitrile, the following is observed: (1) the saturation capacity is higher for acetonitrile, (2) the equilibrium constant for the adsorbent, $b_{\mathrm{s}}$, is almost twice as large for methanol, and (3) the equilibrium constant for the adsorbed solute layer, $b_{\mathrm{L}}$, is almost equal to that for methanol. Previously, it has been shown that acetonitrile adsorbs in multilayers to the $\mathrm{C}_{18}$ chains, while methanol adsorbs in a monolayer $[18,40]$. The thicker acetonitrile layer can dissolve more solute molecules from the bulk than can the bonded $\mathrm{C}_{18}$ layer alone, which could be the reason for the trile, the flow rate was $1.0 \mathrm{~mL} \mathrm{m^{-1 }}$ and injections were $0.5 \mathrm{~mL}$ of a $2.5 \mathrm{~g} \mathrm{~L}^{-1}$ solution. For methanol, the flow rate was $0.7 \mathrm{~mL} \mathrm{~min}^{-1}$ and injections were $0.5 \mathrm{~mL}$ of a $4.0 \mathrm{~g} \mathrm{~L}^{-1}$ solution. The column temperature was $30{ }^{\circ} \mathrm{C}$ in all experiments. Note that for the $\mathrm{pH}$-dependent model, one set of numerical parameters is used at all $\mathrm{pH}$ levels, while for the quadratic model, a different parameter set is used at each $\mathrm{pH}$

higher saturation capacity. The acetonitrile multilayer could also explain the lower $b_{\mathrm{s}}$ with acetonitrile, since omeprazole molecules have more difficulty interacting with the $\mathrm{C}_{18}$ chains due to the thicker acetonitrile layer. From the above speculation, one could expect that omeprazole has a similar $b_{\mathrm{L}}$ with acetonitrile and with methanol, since this reflects the interaction between omeprazole molecules surrounded by the mobile phase, which consists mainly of water in both the cases. The magnitude of $b_{\mathrm{s}}$ relative to $b_{\mathrm{L}}$ with the two modifiers indicates that adsorbate-adsorbate interactions are more favored in acetonitrile than in methanol, which is believed to be the main reason for the change in peak shape for uncharged omeprazole when switching organic modifier.

\section{Conclusions}

The adsorption of omeprazole as a function of $\mathrm{pH}$ for two organic modifiers, acetonitrile and methanol, has been investigated through adsorption isotherm characterization. The aim was to determine an adsorption isotherm model for the adsorption of omeprazole to demonstrate how such knowledge could provide complementary information to support the chemometric modeling commonly used in the QbD framework. The system considered here contained 
omeprazole along with two of its impurities, and the buffer $\mathrm{pH}$ and temperature were varied in a DoE investigation.

From the DoE results, it appeared that the selectivity differed between acetonitrile and methanol as modifiers, omeprazole having the critical resolution factor with omeprazole sulfone in acetonitrile and with methyl-omeprazole in methanol. This was explained partly by the differences in the mobile phase $\mathrm{pH}$ and $\mathrm{p} K_{\mathrm{a}}$ values of the solutes in the acetonitrile and methanol mobile phases. Furthermore, the DoE results also revealed that omeprazole was tailing with methanol and fronting with acetonitrile, along with increased fronting at high $\mathrm{pH}$. These observations could not be explained by the DoE results, so after confirming that the underlying origin of the asymmetry was thermodynamic, the adsorption isotherms were determined to deepen the understanding.

The increase in fronting with $\mathrm{pH}$ in the acetonitrile case was understood by fitting a $\mathrm{pH}$-dependent adsorption isotherm simultaneously to all mobile-phase $\mathrm{pH}$ values. This model contains the fractions of neutral omeprazole molecules, which are, implicitly, a function of the local mobilephase $\mathrm{pH}$ in the solute band. The $\mathrm{pH}$-dependent model agreed well with the experimental data and indicated that the peaks exhibit more fronting at high $\mathrm{pH}$ due to a larger fraction of charged omeprazole molecules. This model could also accurately predict overloaded elution profiles at arbitrary $\mathrm{pH}$ in the studied interval.

The difference between acetonitrile and methanol was studied at the lowest $\mathrm{pH}$ at which almost all omeprazole molecules are in the neutral state, using a two-layer adsorption isotherm model. From the determined adsorption isotherms, we found that (1) the saturation capacity was larger with acetonitrile, (2) the association equilibrium constant for adsorbate-adsorbent interactions is about a factor two higher with methanol, and (3) the association equilibrium constant for adsorbate-adsorbate interactions is similar for the two organic modifiers. Points (1) and (2) were believed to be due to the adsorbed multilayers of acetonitrile making it possible to dissolve more solute molecules from the bulk than could the bonded layer alone making it more difficult for omeprazole molecules to interact with the $\mathrm{C}_{18}$ chains due to the thickness of the acetonitrile layer. The acetonitrile multilayer lowered the solute-adsorbent equilibrium constant, since omeprazole molecules have more difficulty interacting with the $\mathrm{C}_{18}$ chains due to the thick acetonitrile layer. The difference in relative strength between the two equilibrium constants for the two modifiers is believed to cause the "Langmuir"/"anti-Langmuir" difference.

We strongly believe that thermodynamic modeling can be a useful tool to complement chemometric models for the HPLC method validation in the QbD framework. Additional scientific-based information beside the DoE investigation is of high importance to present and find acceptance for an enhanced QC-method concept. Depths in scientific knowledge make it possible for the regulatory agencies to give the pharmaceutical industry an increased flexibility that allow continuous improvement of regulatory approved QC methods. Thereby, a high-quality release process of product batches can be maintained during the whole life cycle of the product. An improved understanding of the separation process and the ability to predict the shape of overloaded elution profiles can be achieved at the cost of only a few more experiments.

Acknowledgments This work was supported by the Swedish Knowledge Foundation via the project "SOMI: Studies of Molecular Interactions for Quality Assurance, Bio-Specific Measurement \& Reliable Supercritical Purification" (Grant Number 20140179), by the ÅForsk Foundation via the project "Improved Purification Procedures to Satisfy Modern Drug Quality Assurance and Environmental Criteria" (Grant Number 15/497) and by Grant 2015/18/M/ST8/00349 from the National Science Centre, Poland. The work was partly supported also by the Swedish Research Council (VR) in the project "Fundamental Studies on Molecular Interactions aimed at Preparative Separations and Bio-Specific Measurements" (Grant Number 2015-04627). We are also grateful to Mikael Nilsson at Cambrex R\&D Karlskoga and to Jakob Rajgård at Waters for most valuable discussions.

\section{Compliance with ethical standards}

Conflict of interest All authors declare that they have no conflict of interest.

Ethical approval This article does not contain any studies with human participants or animal performed by any of the authors.

Open Access This article is distributed under the terms of the Creative Commons Attribution 4.0 International License (http://creativecommons.org/licenses/by/4.0/), which permits unrestricted use, distribution, and reproduction in any medium, provided you give appropriate credit to the original author(s) and the source, provide a link to the Creative Commons license, and indicate if changes were made.

\section{References}

1. Görög S (2007) The changing face of pharmaceutical analysis. Trends Anal Chem 26:12-17. doi:10.1016/j.trac.2006.07.011

2. Yu LX, Amidon G, Khan MA et al (2014) Understanding pharmaceutical quality by design. AAPS J 16:771-783. doi:10.1208/ s12248-014-9598-3

3. Yu LX (2008) Pharmaceutical quality by design: product and process development, understanding, and control. Pharm Res 25:781-791. doi:10.1007/s11095-007-9511-1

4. Rozet E, Lebrun P, Hubert P et al (2013) Design spaces for analytical methods. Trends Anal Chem 42:157-167. doi:10.1016/j. trac.2012.09.007

5. Schmidt AH, Molnár I (2013) Using an innovative qualityby-design approach for development of a stability indicating UHPLC method for ebastine in the API and pharmaceutical formulations. J Pharm Biomed Anal 78-79:65-74. doi:10.1016/j. jpba.2013.01.032

6. EMA/430501/2013 Document (2013) EMA-FDA pilot program for parallel assessment of quality-by-design applications: lessons 
learnt and Q\&A resulting from the first parallel assessment. EMA, London. http://www.ema.europa.eu. Accessed 1 Jul 2016

7. Vogt FG, Kord AS (2011) Development of quality-by-design analytical methods. J Pharm Sci 100:797-812. doi:10.1002/jps.22325

8. Do DD (1998) Adsorption analysis: equilibria and kinetics. Imperial College Press, London

9. Samuelsson J, Arnell R, Fornstedt T (2009) Potential of adsorption isotherm measurements for closer elucidating of binding in chiral liquid chromatographic phase systems. J Sep Sci 32:14911506. doi:10.1002/jssc.200900165

10. Samuelsson J, Franz A, Stanley BJ, Fornstedt T (2007) Thermodynamic characterization of separations on alkaline-stable silicabased $\mathrm{C} 18$ columns: why basic solutes may have better capacity and peak performance at higher $\mathrm{pH}$. J Chromatogr A 1163:177189. doi:10.1016/j.chroma.2007.06.026

11. Gritti F, Guiochon G (2004) Retention of ionizable compounds in reversed-phase liquid chromatography. effect of the ionic strength of the mobile phase and the nature of the salts used on the overloading behavior. Anal Chem 76:4779-4789. doi:10.1021/ac0304121

12. Enmark M, Samuelsson J, Undin T, Fornstedt T (2011) Characterization of an unusual adsorption behavior of racemic methylmandelate on a tris-(3,5-dimethylphenyl) carbamoyl cellulose chiral stationary phase. J Chromatogr A 1218:6688-6696. doi:10.1016/j.chroma.2011.07.064

13. Åsberg D, Leśko M, Samuelsson J et al (2014) Method transfer from high-pressure liquid chromatography to ultra-high-pressure liquid chromatography. I. A thermodynamic perspective. J Chromatogr A 1362:206-217. doi:10.1016/j.chroma.2014.08.051

14. Olbe L, Carlsson E, Lindberg P (2003) A proton-pump inhibitor expedition: the case histories of omeprazole and esomeprazole. Nat Rev Drug Discov 2:132-139. doi:10.1038/nrd1010

15. Åsberg D, Samuelsson J, Leśko M et al (2015) Method transfer from high-pressure liquid chromatography to ultra-high-pressure liquid chromatography. II. Temperature and pressure effects. J Chromatogr A 1401:52-59. doi:10.1016/j.chroma.2015.05.002

16. Åsberg D, Nilsson $\mathrm{M}$, Olsson $\mathrm{S}$ et al A quality control method enhancement concept-continual improvement of regulatory approved QC methods. J Pharm Biomed Anal. doi:10.1016/j. jpba.2016.06.018

17. Sing KSW, Everett DH, Haul RAW et al (1985) Reporting physisorption data for gas/solid systems with special reference to the determination of surface area and porosity. Pure Appl Chem 57:603-619. doi:10.1351/pac198557040603

18. Gritti F, Guiochon G (2005) Adsorption mechanism in RPLC. Effect of the nature of the organic modifier. Anal Chem 77:42574272. doi:10.1021/ac0580058

19. Gritti F, Guiochon G (2009) Peak shapes of acids and bases under overloaded conditions in reversed-phase liquid chromatography, with weakly buffered mobile phases of various $\mathrm{pH}$ : a thermodynamic interpretation. J Chromatogr A 1216:63-78. doi:10.1016/j.chroma.2008.11.020

20. Gritti F, Guiochon G (2009) Adsorption mechanism of acids and bases in reversed-phase liquid chromatography in weak buffered mobile phases designed for liquid chromatography/mass spectrometry. J Chromatogr A 1216:1776-1788. doi:10.1016/j. chroma.2008.10.064

21. Gritti F, Guiochon G (2009) Band profiles of reacting acidobasic compounds with water-methanol eluents at different and ionic strengths in reversed-phase liquid chromatography. J Chromatogr A 1216:3175-3184

22. Gritti F, Guiochon G (2004) Influence of a buffered solution on the adsorption isotherm and overloaded band profiles of an ionizable compound. J Chromatogr A 1028:197-210. doi:10.1016/j. chroma.2003.11.106
23. Mihlbachler K, Kaczmarski K, Seidel-Morgenstern A, Guiochon $G$ (2002) Measurement and modeling of the equilibrium behavior of the Tröger's base enantiomers on an amylose-based chiral stationary phase. J Chromatogr A 955:35-52. doi:10.1016/ S0021-9673(02)00228-5

24. Mihlbachler K, De Jesús MA, Kaczmarski K et al (2006) Adsorption behavior of the ( \pm )-Tröger's base enantiomers in the phase system of a silica-based packing coated with amylose tri(3,5-dimethyl carbamate) and 2-propanol and molecular modeling interpretation. J Chromatogr A 1113:148-161

25. Ruthven DM (1984) Principles of adsorption and adsorption processes. Wiley-Interscience, New York

26. Moreau M, Valentin P, Vidal-Madjar C et al (1991) Adsorption isotherm model for multicomponent adsorbate-adsorbate interactions. J Colloid Interface Sci 141:127-136. doi:10.1016/0021-9797(91)90308-U

27. Guiochon G, Shirazi DG, Felinger A, Katti AM (2006) Fundamentals of preparative and nonlinear chromatography, 2nd edn. Academic Press, Boston

28. Kaczmarski K (2007) Estimation of adsorption isotherm parameters with inverse method-Possible problems. J Chromatogr A 1176:57-68. doi:10.1016/j.chroma.2007.08.005

29. Kaczmarski K, Mazzotti M, Storti G, Mobidelli M (1997) Modeling fixed-bed adsorption columns through orthogonal collocations on moving finite elements. Comput Chem Eng 21:641-660. doi:10.1016/S0098-1354(96)00300-6

30. Brown P, Byrne G, Hindmarsh A (1989) VODE: a variablecoefficient ODE solver. SIAM J Sci Stat Comput 10:1038-1051. doi: $10.1137 / 0910062$

31. Fletcher R (1971) A modified Marquardt sub-routine for non-linear least squares. Atomic Energy Research Establishment, Harwell

32. Gritti F, Kazakevich Y, Guiochon G (2007) Measurement of holdup volumes in reverse-phase liquid chromatography: definition and comparison between static and dynamic methods. J Chromatogr A 1161:157-169. doi:10.1016/j.chroma.2007.05.102

33. Rosés M, Bosch E (2002) Influence of mobile phase acidbase equilibria on the chromatographic behaviour of protolytic compounds. J Chromatogr A 982:1-30. doi:10.1016/ S0021-9673(02)01444-9

34. Horvath C, Melander W, Molnar I (1977) Liquid chromatography of ionogenic substances with nonpolar stationary phases. Anal Chem 49:142-154. doi:10.1021/ac50009a044

35. Arvidsson T, Collijn E, Tivert A-M, Rosén L (1991) Peak distortion in the column liquid chromatographic determination of omeprazole dissolved in borax buffer. J Chromatogr A 586:271-276. doi:10.1016/0021-9673(91)85132-Y

36. Scopes RK (1994) Protein purification. Springer, New York

37. Reijenga JC, Gagliardi LG, Kenndler E (2007) Temperature dependence of acidity constants, a tool to affect separation selectivity in capillary electrophoresis. J Chromatogr A 1155:142145. doi:10.1016/j.chroma.2006.09.084

38. Gavin PF, Olsen BA (2008) A quality by design approach to impurity method development for atomoxetine hydrochloride (LY139603). J Pharm Biomed Anal 46:431-441. doi:10.1016/j. jpba.2007.10.037

39. Schmidt AH, Wess C (2013) A QbD with design-of-experiments approach for development of a state-of-the-art UPLC purity method for carbamazepine. J Liq Chromatogr Relat Technol 37:2653-2666. doi:10.1080/10826076.2013.853312

40. Kazakevich Y, LoBrutto R, Chan F, Patel T (2001) Interpretation of the excess adsorption isotherms of organic eluent components on the surface of reversed-phase adsorbents: effect on the analyte retention. J Chromatogr A 913:75-87. doi:10.1016/ S0021-9673(00)01239-5 